\title{
NUMERICAL INVESTIGATION OF RC BEAMS STRENGTHENED WITH PRESTRESSED CFRP
}

\author{
Mykolas DAUGEVIČIUS \\ Vilnius Gediminas Technical University, Sauletekio al. 11, 10223 Vilnius, Lithuania \\ Received 02 February 2017; accepted 14 September 2017
}

\begin{abstract}
Different strengthening technique was evaluated in order to investigate the effect of prestress. The analysed beams were strengthened with non-prestressed CFRP and prestressed CFRP at different loading levels. It has allowed a better understanding about strengthening effectiveness. Results obtained by finite element analysis were compared with experimental results obtained by other researchers. Phased nonlinear analysis was used to simulate the behaviour of the strengthened beams. Performed analysis showed that it is possible to use finite element analysis in order to investigate a real behaviour of the strengthened elements in real structure.
\end{abstract}

Keywords: strengthening, prestressed CFRP, numerical investigation, deflection, depth of neutral axis.

\section{Introduction}

Flexural strengthening of beams with non-prestressed CFRP usually increases a load carrying capacity of the beam. Meanwhile an initial deflection remains the same. Only after an increment of external load the positive influence strengthening with CFRP can be distinguished, because the increment of deflections becomes smaller. In order to decrease initial deflection prestress load of CFRP should be transferred in to the strengthened beam. Most studies (Quantrill, Hollaway 1998; Garden et al. 1998; Huang et al. 2005; Yang et al. 2009; Shang et al. 2010; Xue et al. 2010; Si-Larbi et al. 2012; Liang et al. 2016a, 2016b) applied prestressed FRP, before external load was added. In summary, these studies may highlight that after strengthening with prestressed FRP material not only the cracking moment increases, but as well the moment when the yielding of tensioned reinforcement is being reached. A distribution of internal resultant forces in the crosssection can be different if the beams will be strengthened under external load action. So the above mentioned accomplished researches not always reflect the actual behaviour of the strengthened beam. There is one research accomplished by Kotynia et al. (2014), where RC slabs were strengthened with prestressed CFRP under external load action. It is important that the RC slabs before strengthening were cracked in the above-mentioned research (later slabs will be considered as beams). Different distribution of internal resultant forces can be distinguished, before strengthening and after strengthening. Different flexural stiffness as well. Research of Badawi and Soudki (2009) shows that when the prestressed CFRP is applied stresses decrease in the compressed concrete and tensioned steel bars. Thus load carrying capacity of the beams with prestressed CFRP has increased. Another research (Woo et al. 2008) shows that the bigger increase of the load carrying capacity is obtained with the lower prestress level. Research conducted by Deng and Xiao (2010) showed that prestress level did not influence the increment of load carrying capacity, but influenced the increase of cracking moment and yielding moment. Meanwile Garden and Hollaway (1998) indicated that failure mode of the strengthened beam de- 
pends on the degree of prestressing. For example, the beams in research of Badawi and Soudki (2009) without prestressed CFRP failed by crushing of compressed concrete, and beams with prestressed CFRP failed by rupture of the CFRP layer. Contradiction associated with the increment of the load carrying capacity after prestressing of CFRP can be explained by the development of shear stresses in the bond of CFRP in concrete. The research of Diab et al. (2009) showed that plastic shear strains increase were the maximal shear stresses act, and this is happening at the ends of the CFRP laminate. Therefore the failure of strengthened beam may occur because of peeling off or debonding of CFRP laminate and it may happen before the increment of load carrying capacity of reinforced beam may occur. Thus, on the basis that in most of the studies the beams was strengthened without the external load action, a nonlinear numerical analysis was carried out on the basis of Kotynia et al. (2014) experimental research. As it was already mentioned, the RC slabs in research of Kotynia et al. (2014) were strengthened under external load action. So it is interesting to compare the behaviour of strengthened beams predicted by FEA with experimental, when the more realistic strengthening scenario was applied.

\section{Analysed samples and FEA}

Extensive research related on strengthening RC beams with prestressed CFRP permits to perform a nonlinear finite element analysis of the tested beams. For this purpose research conducted by Kotynia et al. (2014) contains the most appropriate elements to analyse. The mentioned research is different from others because the strengthening of beams was more in line with actual construction work conditions. The author argues that the beams were strengthened with prestressed CFRP under acting of external load. So selected beams for nonlinear finite element analysis and reinforcement parameters are presented in Table 1. In this Table by the author the control beams B12, B16 without strengthening and beam B16-a strengthened with non-prestressed CFRP were additionally created. Mentioned beams have not been investigated in the Kotynia et al. (2014) article. So the author has created additional FEA models in order to carry out a broader comparison. Finite element analysis program DIANA developed by TNO DIANA (user's manual by Manie and Kikstra (2011)) was used in order to perform numerical nonlinear analysis.

Finite analysis model of analysed beams are presented in Figure 1. Quadrilateral finite elements were used to make a model of the analysed beams. Just half of beam was modelled, because symmetry of the crosssection was evaluated. Steel bars were modelled like "bar in solid" elements. Layer of CFRP was modelled as "2D Plane Stress" elements, thickness of which was $1.2 \mathrm{~mm}$. External load was transferred through the steel plates. Also the beam was supported on the steel plates, one of which was like a mobile support. Prestress effect was assigned for $2 \mathrm{D}$ plane stress elements. So totally the three load sets were created: body load, external load, prestress load.

Table 1. List of analyzed beams and mechanical parameters of reinforcement materials

\begin{tabular}{|c|c|c|c|c|c|c|c|}
\hline Source & Sample name & $b \times h, m m$ & $A_{s}, m m^{2}$ & $f_{y}, M P a$ & $E_{s}, G P a$ & $f_{f}, M P a$ & $E_{f}, G P a$ \\
\hline \multirow{8}{*}{$\begin{array}{l}\text { Kotynia } \\
\text { et al. } 2014\end{array}$} & \multirow{2}{*}{ B12-a } & \multirow{8}{*}{$500 \times 220$} & \multirow{2}{*}{$\begin{array}{c}4 \varnothing 8,4 \times 49.4 \\
4 \varnothing 12,4 \times 113.3\end{array}$} & 416.2 & 186.1 & \multirow{8}{*}{2857.0} & \multirow{8}{*}{173.3} \\
\hline & & & & 539.6 & 191.3 & & \\
\hline & \multirow{2}{*}{ B12-asp } & & \multirow{2}{*}{$\begin{array}{c}4 \varnothing 8,4 \times 48.9 \\
4 \varnothing 12,4 \times 111,0\end{array}$} & 583.1 & 200.7 & & \\
\hline & & & & 511.4 & 191.1 & & \\
\hline & \multirow{2}{*}{ B12-asp-e } & & \multirow{2}{*}{$\begin{array}{c}4 \varnothing 8,4 \times 49.4 \\
4 \varnothing 12,4 \times 113.3\end{array}$} & 416.2 & 186.1 & & \\
\hline & & & & 539.6 & 191.3 & & \\
\hline & B16-asp & & \multirow{2}{*}{$\begin{array}{c}4 \varnothing 8,4 \times 48.8 \\
4 \varnothing 16,4 \times 199.1\end{array}$} & 555.8 & 196.4 & & \\
\hline & B16-asp-e & & & 595.0 & 198.0 & & \\
\hline \multirow{4}{*}{$\begin{array}{l}\text { Author, } \\
\text { FEA }\end{array}$} & \multirow{2}{*}{ B12 } & \multirow{4}{*}{$500 \times 220$} & \multirow{2}{*}{$\begin{array}{c}4 \varnothing 8,4 \times 49.4 \\
4 \varnothing 12,4 \times 113.3\end{array}$} & 416.2 & 186.1 & \multirow{4}{*}{2857.0} & \multirow{4}{*}{173.3} \\
\hline & & & & 539.6 & 191.3 & & \\
\hline & B16 & & \multirow{2}{*}{$\begin{array}{c}4 \varnothing 8,4 \times 48.8 \\
4 \varnothing 16,4 \times 199.1\end{array}$} & 555.8 & 196.4 & & \\
\hline & B16-a & & & 595.0 & 198.0 & & \\
\hline
\end{tabular}



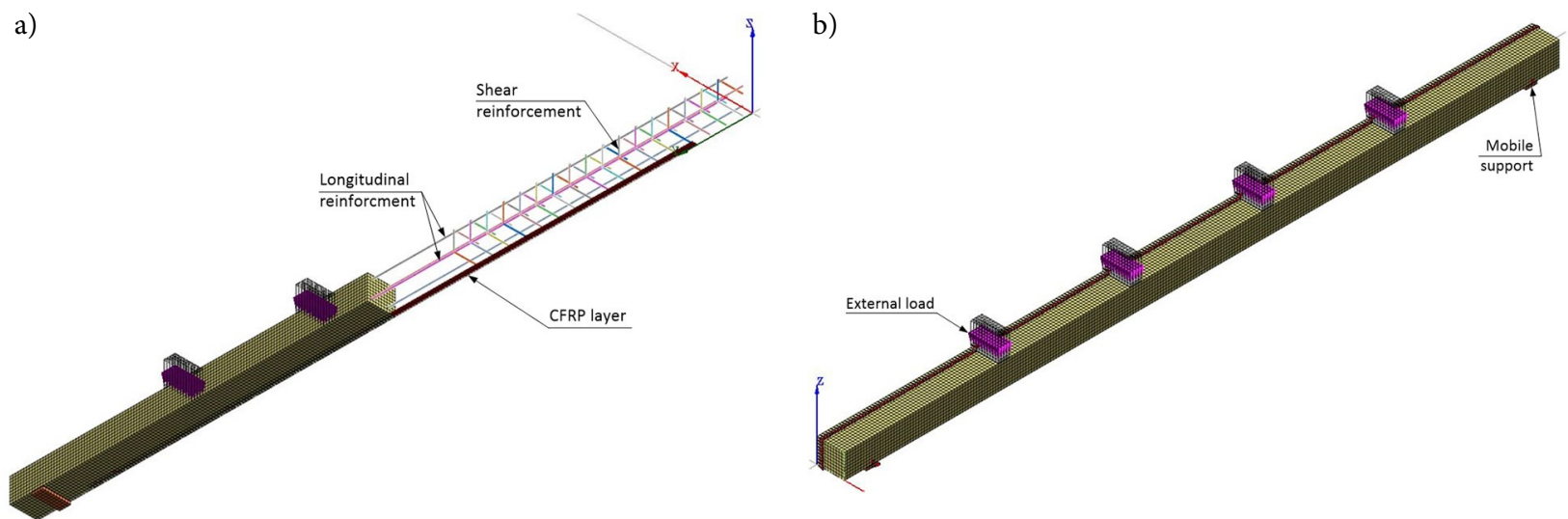

Fig. 1. FEA models of analyzed beams: $\mathrm{a}$ - internal and external reinforcement; $\mathrm{b}$ - loading scheme

Particular mechanical parameters are required in order to perform nonlinear analysis. Concrete mechanical parameters from Kotynia et al. (2014) research were coupled in the Table 2. These parameters are required in order to evaluate concrete fracture energy.

Fracture energy of tensile concrete was predicted by CEB-FIP Model Code 1990 Equation:

$$
G_{F}=G_{F 0} \cdot\left(f_{c m} / f_{c m 0}\right)^{0.7} \text {. }
$$

Here $G_{F 0}$ - the base value of fracture energy which was equal to $0.03\left(\mathrm{Nmm} / \mathrm{mm}^{2}\right)$ and $f_{c m 0}=10 \mathrm{MPa}$.

Fracture energy of compressive concrete was evaluated according to the equation that was predicted by Lourenco P. B. (1996):

$$
G_{f_{c}}=15+0.43 \cdot f_{c}-0.0036 f_{c}^{2} .
$$

Here $f_{c}$ - compressive strength of concrete used from Table 2 .

Tensile strength of concrete material predicted by Eurocode 2 (EN 1992-1-1:2004) equation:

$$
f_{c t}=0.9 \cdot f_{c t . s p} .
$$

Here $f_{c t, s p}$ - tensile splitting strength of concrete used from Table 2.
Calculated values by Equations (1), (2) and (3) required to perform nonlinear analysis are presented in Table 3.

Nonlinear analysis of investigated beams requires a certain execution process. In order to perform analysis of beams strengthened with prestressed CFRP, the phased nonlinear analysis should be done. Table 4 describes analysis process of all beams. In order to perform the nonlinear analysis of beams B12, B16, $\mathrm{B} 12-\mathrm{a}, \mathrm{B} 16-\mathrm{a}$ the phased analysis were not necessary. At the beginning these beams were loaded by body load and then with external load. The phased analysis was necessary for the rest of the beams. At the first analysis phase, beams B12-asp, B16-asp were loaded by the body force. Layer of CFRP was not incorporated in the analysed model. At the second analysis phase prestressed CFRP layer was incorporated in the beams B12-asp, B16-asp model. This was carried out by creating new execute block. Start steps were added in this block and the initial stress from prestressed CFRP load set was evaluated. The next execute block has evaluated increment of external load till failure of the strengthened element. At the first analysis phase the

\begin{tabular}{|c|c|c|c|c|c|}
\hline Source & Sample name & $b x h, m m$ & $f_{c^{\prime}}, M P a$ & $f_{c t, s p}, M P a$ & $E_{c}, G P a$ \\
\hline \multirow{5}{*}{$\begin{array}{c}\text { Kotynia et al. } \\
2014\end{array}$} & B12-a & \multirow{5}{*}{$500 \times 220$} & 45.3 & 3.6 & 24.3 \\
\hline & B12-asp & & 32.2 & 2.65 & 23.7 \\
\hline & B12-asp-e & & 41.6 & 3.5 & 24.7 \\
\hline & B16-asp & & 49.0 & 3.65 & 25.4 \\
\hline & B16-asp-e & & 51.0 & 5.3 & 26.4 \\
\hline \multirow{3}{*}{ Author, FEA } & B12 & \multirow{3}{*}{$500 \times 220$} & 45.3 & 3.6 & 24.3 \\
\hline & B16 & & \multirow{2}{*}{49.0} & \multirow{2}{*}{3.65} & \multirow{2}{*}{25.4} \\
\hline & B16-a & & & & \\
\hline
\end{tabular}
beams B12-asp-e, B16-asp-e were loaded by the body

Table 2. Mechanical parameters of concrete 
Table 3. Parameters of materials for nonlinear analysis

\begin{tabular}{|c|c|c|c|c|}
\hline \multirow{2}{*}{\multicolumn{2}{|c|}{ Sample name and source }} & \multicolumn{3}{|c|}{ Calculated values } \\
\hline & & $G_{F}$ & $G_{C}$ & $f_{c t}, M P a$ \\
\hline B12-a & \multirow{5}{*}{$\begin{array}{c}\text { Kotynia et al. } \\
2014\end{array}$} & 0.086 & 27.091 & 3.24 \\
\hline B12-asp & & 0.068 & 25.113 & 2.385 \\
\hline B12-asp-e & & 0.081 & 26.66 & 3.15 \\
\hline B16-asp & & 0.091 & 27.43 & 3.285 \\
\hline B16-asp-e & & 0.094 & 27.57 & 4.77 \\
\hline $\mathrm{B} 12$ & \multirow{3}{*}{ Author, FEA } & 0.086 & 27.091 & 3.24 \\
\hline B16 & & \multirow{2}{*}{0.091} & \multirow{2}{*}{27.43} & \multirow{2}{*}{3.285} \\
\hline B16-a & & & & \\
\hline
\end{tabular}

Table 4. Steps and description of numerical analysis

\begin{tabular}{|c|c|c|c|}
\hline Name & Phase & Description & Equilibrium iteration \\
\hline \multirow{2}{*}{$\mathrm{B} 12 ; \mathrm{B} 16$} & I & Self-weight load evaluated & \multirow{10}{*}{$\begin{array}{l}\text { Method: Newton-Raphson, } \\
\text { max. } 200 \text { iterations. } \\
\text { Convergence norm according } \\
\text { to displacement }\end{array}$} \\
\hline & I & Beams loaded till failure & \\
\hline \multirow{2}{*}{ B12-a; B16-a } & I & Self-weight load evaluated & \\
\hline & I & Beams loaded till failure & \\
\hline \multirow{2}{*}{$\begin{array}{l}\text { B12-asp; } \\
\text { B16-asp }\end{array}$} & I & Beams loaded with self-weight load & \\
\hline & II & CFRP layer incorporated and beams loaded till failure & \\
\hline \multirow{4}{*}{ B12-asp-e; B16-asp-e } & $\mathrm{I}$ & Beams loaded with self-weight load & \\
\hline & I & Beams loaded till appropriate load level & \\
\hline & \multirow{2}{*}{ II } & Prestressed CFRP layer applied & \\
\hline & & Beams loaded till failure & \\
\hline
\end{tabular}

force and then by external load set till appropriate load level. As well layer of CFRP was not incorporated in the first phase of analysis. At the second analysis phase prestressed CFRP layer was incorporated. As well this was carried out by creating new execute block. Start steps were added in this block and the initial stress from prestressed CFRP load set was evaluated. In the next execute block the increment of external load till failure of the strengthened element was evaluated.

\section{Results and discussion}

Analyzed beams varied by the strengthening manner. Despite this the development of deflection it is possible to divide into separate stages. At each stage different stress-strain distribution develops in the cross-section of the analyzed elements. The first stage continues till the first normal cracks open in the tensioned concrete area. The second stage continues till the steel yielding is reached in the tensioned steel bars. The third stage continues till the failure or the CFRP layer will fail. And it doesn't matter in what manner (rupture, delamination, peeling of) the CFRP layer will fail. Numerically predicted load-deflection curves are presented in Figures 2 and 3. It is clear that after strengthening the flexural stiffness has increased and the increment of deflection has become smaller. Also the cracking moment has increased. Comparison of load-deflection curves shows that the biggest increase of cracking moment is in beams (B12-asp and B16-asp) which were prestressed before the external load was applied. This will be the first advantage of the prestressing. However the continuing comparison of the beams B12-asp, B16-asp and B12-a, B16-a load-deflection curves shows that prestress influenced just increase of cracking moment and yielding moment. It can be seen that the load-deflection curves of the mentioned beams are parallel in the stage two and three. These curves are parallel despite the fact that the depth of neutral axis (Figs 4 and 5) in the beams B12-asp, B16-asp is bigger in comparison with beams B12-a, and B16-a. The second advantage is that prestress increased the load when the yielding of reinforcement is reached. Load level when the yielding 


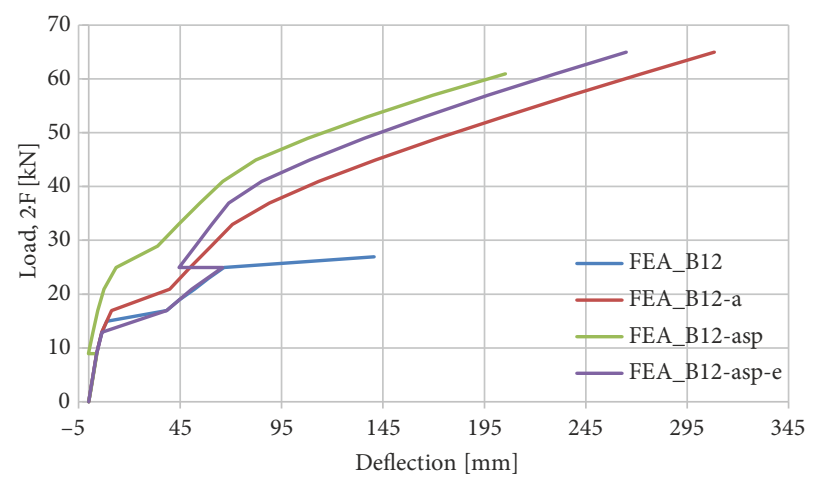

Fig. 2. External load vs deflection, curves predicted numerically. Reinforcement $4 \varnothing 12$

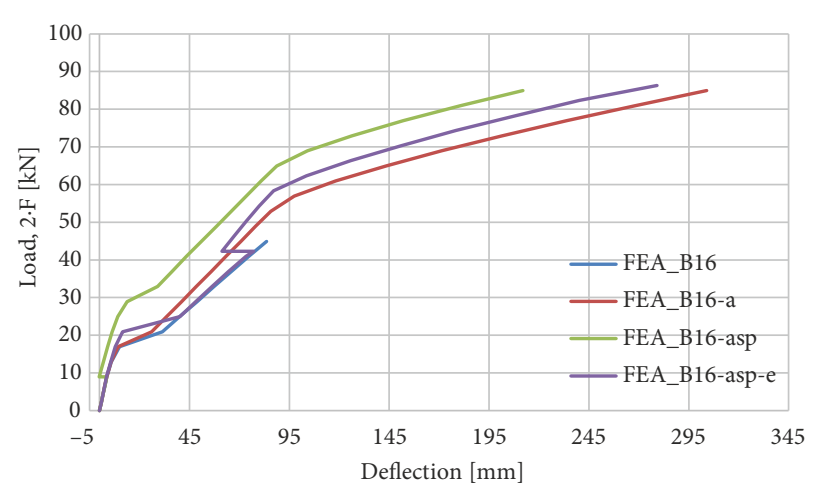

Fig. 3. External load vs deflection curves, predicted numerically. Reinforcement $4 \varnothing 16$

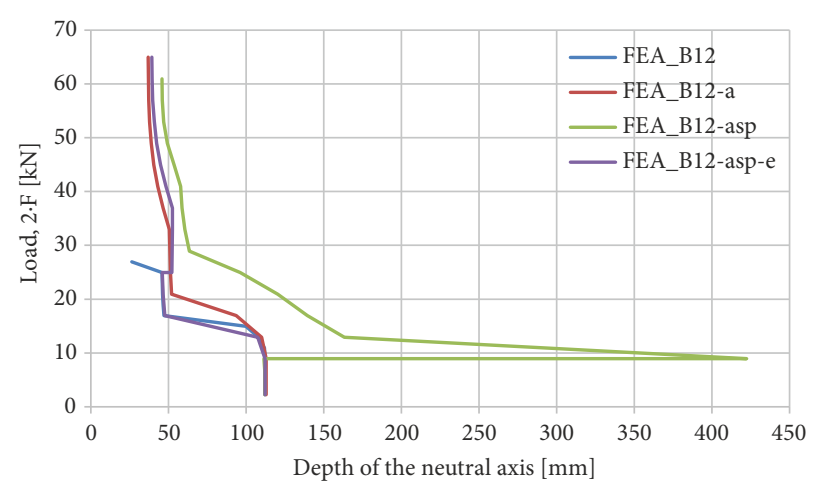

Fig. 4. Depth of the neutral axis predicted numerically. Reinforcement $4 \varnothing 12$

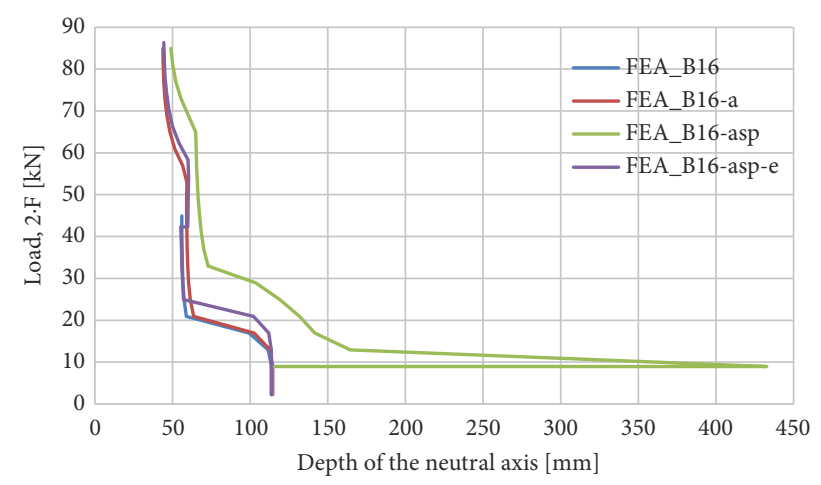

Fig. 5. Depth of the neutral axis predicted numerically. Reinforcement $4 \varnothing 16$ is reached in the beams B12-a and B16-a increases only for one reason. This reason is related with the redistribution of internal resultant forces after strengthening. Resultant force of the tensioned part of the cross-section consists of two parts: resultant force of tensioned steel bars and tensioned CFRP layer. Strengthening of tensioned part of the cross-section requires bigger depth of the neutral axis. Meanwhile the CFRP is an external layer, consequently the distance between the most compressed and tensioned part of cross-section has increased, therefore increment of strains in the tensioned steel bars is less than in case when the beam are not strengthened. Load level, when the yielding is reached in the beams B12-asp, B16-asp and B12-asp-e, B16-asp-e, increases due to two reasons. One of these reasons is mentioned above. The other reason is associated with the prestressing effect. Prestressing of the external CFRP layer determines decreasing of strains distributed along the height of the cross-section. As a result the depth of the neutral axis increases and the new flexural stiffness is created. It can be assumed that the prestressing effect can influence better performance for deformability (increment of deflection). But comparison of the restored deflection shows that it is better to accomplish the prestressing when the tensioned part of the section is cracked. Or it is better to do at the second stage than at the first. Restored deflection, when the prestressing was applied at the first stage, is smaller than at the second stage. Finite element analysis shows that prestressing was accomplished then the yielding of reinforcement was almost reached. This load level for strengthening is too high, but in practice it can occur, especially if the beams were overloaded. So in author's opinion it is better to accomplish prestressing when the external load is near the cracking load value, with the condition that the tensioned part of the section is cracked. If the beam is strengthened with prestressed CFRP before the normal cracks are opened, in this way we can see that compressive stresses are distributed throughout the whole cross-section. Figures 4 and 5 show that the depth of neutral axis goes beyond the limits of cross-section. Prestress load is added on the outer surface of the strengthened element. Consequently due to the prestress load eccentricity a bending moment occurs. And it does not matter that all cross-section is compressed. Due to the bending moment impact the strengthened beam gets a negative curvature and a deflection is restored. In order to eliminate the compressive stresses 
the external load should increase more than in case when the beams are non-prestressed. Thus cracking moment increases. Of course, that increment of cracking load depends on the prestress load.

Comparison of the restored deflection shows that the best prestress effect was obtained on the beams B12-asp-e and B16-asp-e. These beams were cracked. Prestress load is opposite to the resultant tensile force in the tensioned steel bars. Furthermore, the resultant force in the tensioned steel bars has developed from elastic strains in the steel. So prestress load can restore strains in the steel bars and decrease the tensile stresses. Meanwhile prestress load decreases strains and stresses in the compressed part of the cross-section. Thus stress-strain distribution in the section changes and depth of the neutral axis increases, new flexural stiffness is created. Then the beam are loaded with external load, corrupted depth of the neutral axis provides greater stiffness and increment of deflection is smaller in comparison with all other beams. Inclination of load-deflection curve from the ordinate axis is the smallest. Increment of deflection in the beams B12-asp, B16-asp was not affected (i. e. increment after cracking) as well as in beams B12-asp-e, B16asp-e. This happened because after the prestress load was transferred in to the beams B12-asp, B16-asp, the compressive stresses were distributed throughout the whole cross section. As it was stated above, this just increased the cracking moment.

Numerically predicted deflection was compared with research (Kotynia et al. 2014) deflection (Figs 6 and 7). Deflection distribution trend is similar. It should be noted that it was not possible to transfer prestress load in the beam B12-asp-e at the same load level like in research of Kotynia et al. (2014). It could not be possible converge the iteration because yielding of the tensioned reinforcement was reached. Thus the smaller by one loading step load level was used to incorporate prestressed CFRP layer into the analysis. Actually it seems (Figs 2 and 3) that the strengthening of beams B12-asp-e, B16-asp-e was accomplished when the external load almost reached the yielding load. Numerical and experimental deflection can differ due to various reasons. It can be size of the finite quadrilateral elements, loading step size, material nonlinearity model. Nevertheless it is possible to predict cracking and yielding moment. Failure of the finite analysis models was defined according to the extreme stresses (Figs 8 and 9).

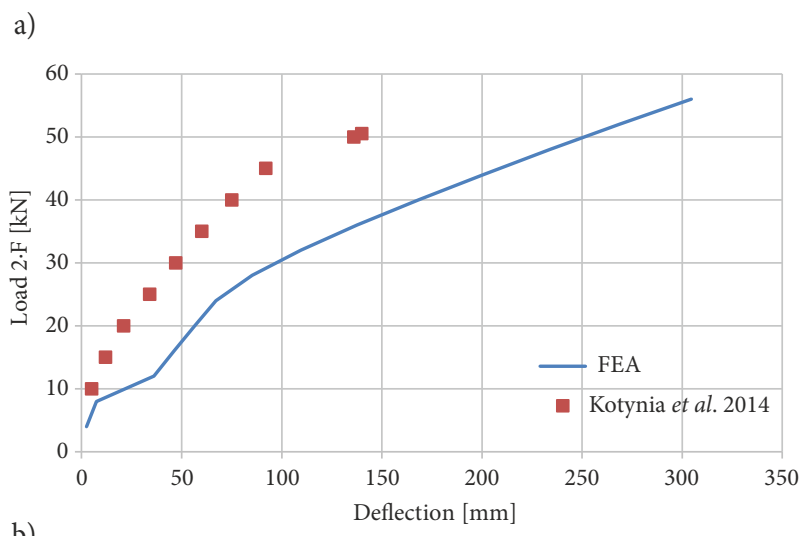

b)

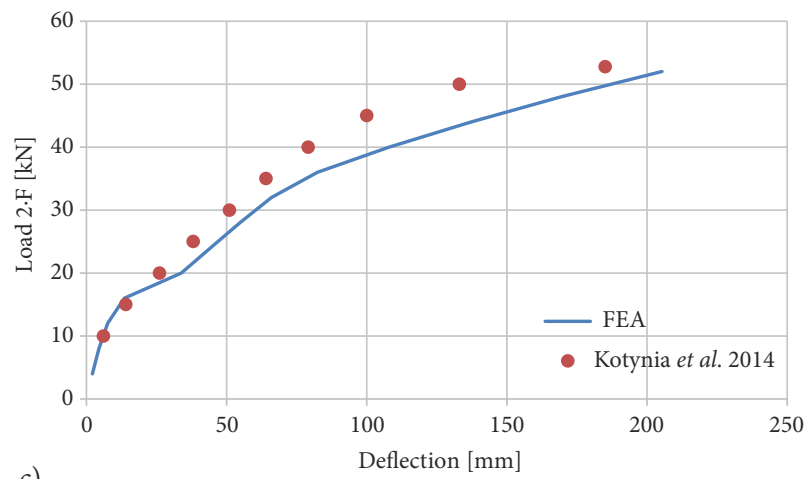

c)

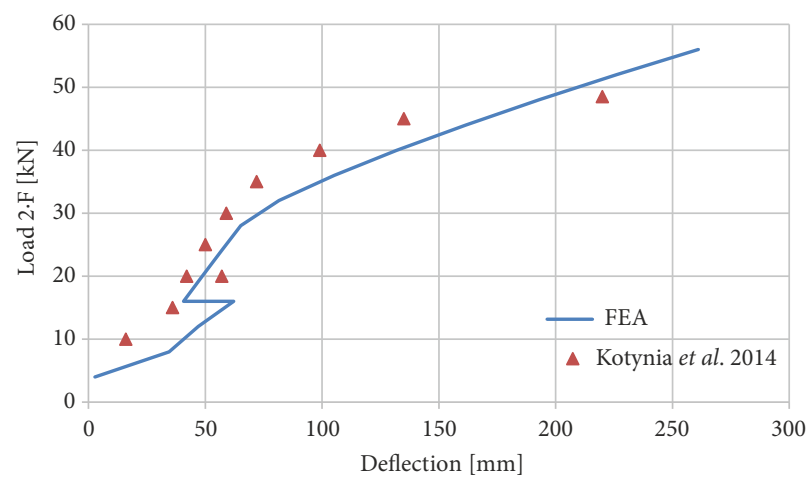

Fig. 6. External load vs deflection, curves predicted numerically and points from research. Reinforcement $4 \varnothing 12$ : a - "a" series beams; b - "asp" series beams; c - "asp-e" series beams (Kotynia et al. 2014)

Development of strains is similar to the not strengthened beams if prestress transferred before the element is cracked. This similarity is valid after the normal cracks open. The better development is obtained in those beams which were strengthened with prestressed CFRP, after the normal cracks were opened. Development of strains in the compressed and tensioned parts of the section decreased. Also growth of the plastic stresses decreased. This allowed maintaining of constant flexural stiffness. Strains near the ultimate load are near the ultimate value of the compressed concrete or tensioned steel and CFRP. 
a)

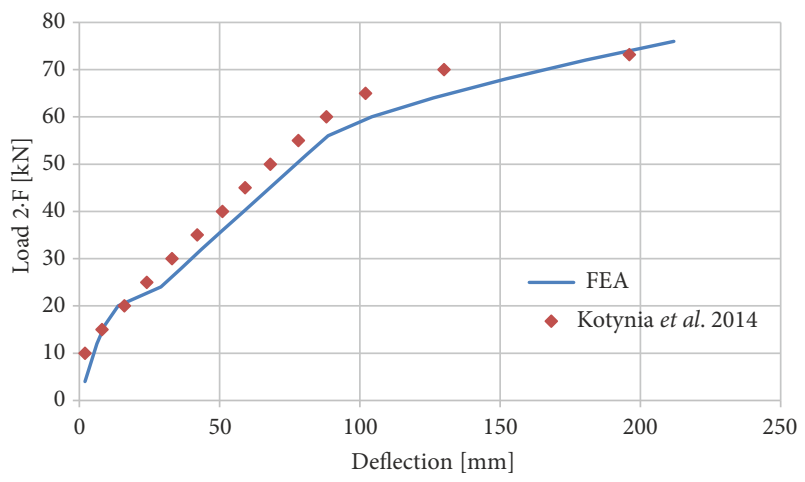

b)

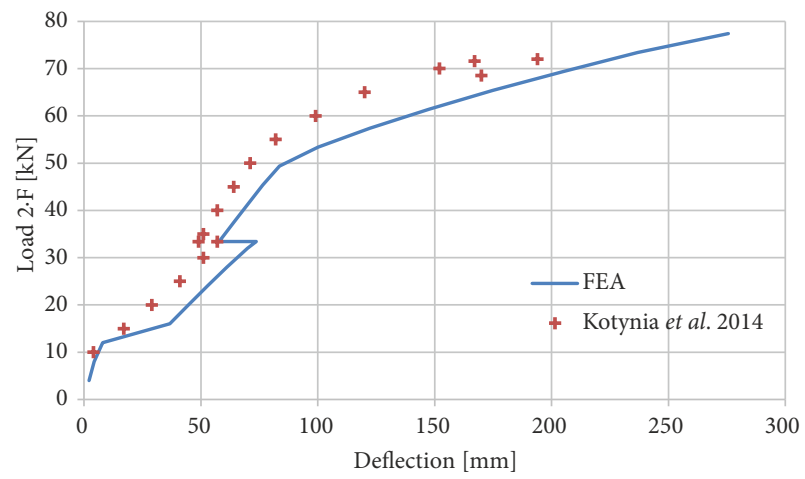

Fig. 7. External load vs deflection, curves predicted numerically and points from research. Reinforcement $4 \varnothing 16$ : a - "asp" series beams; b - "asp-e" series beams (Kotynia et al. 2014)

a)

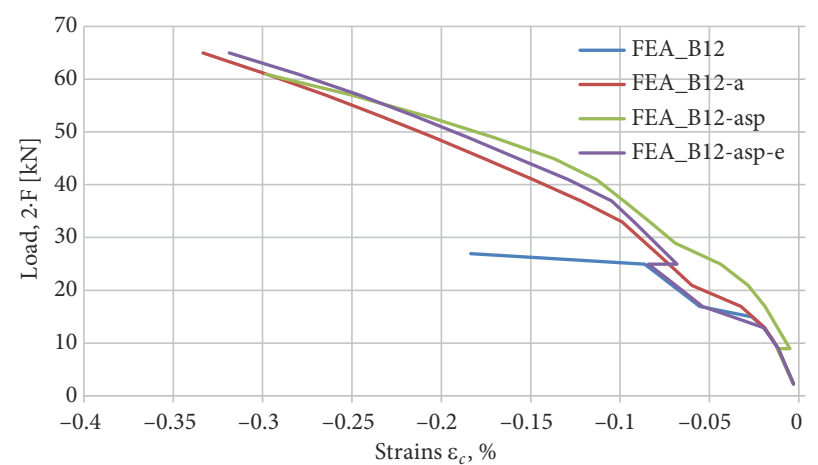

b)

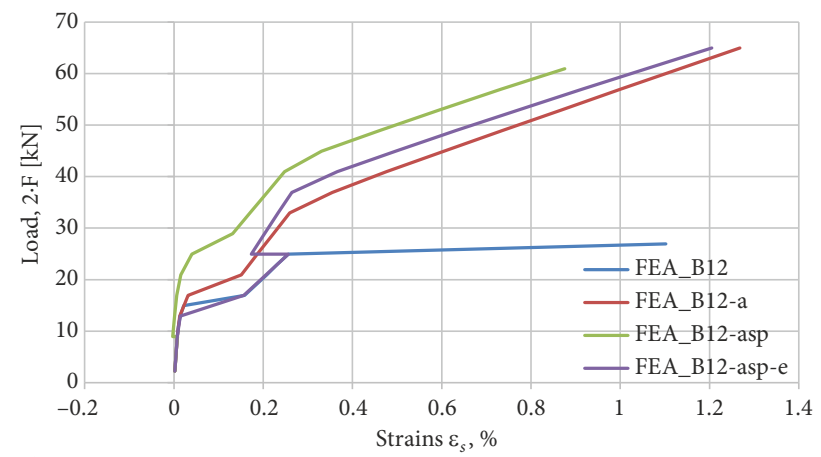

c)

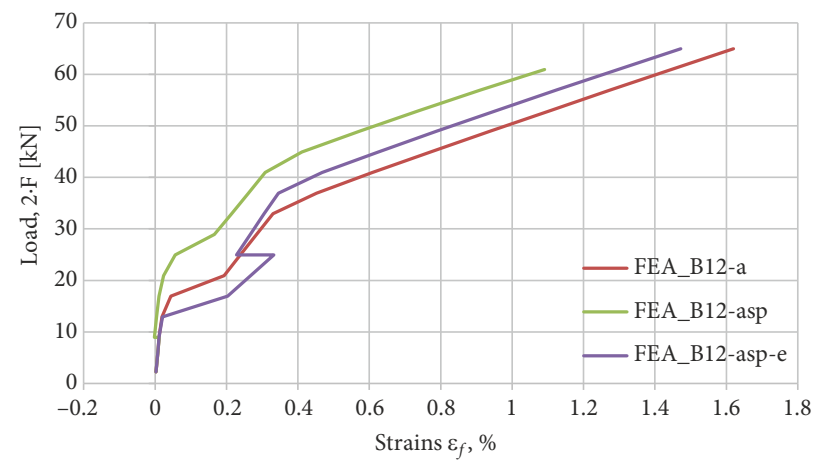

Fig. 8. External load vs strain, curves predicted numerically reinforcement, $4 \varnothing 12: \mathrm{a}-\varepsilon_{c} ; \mathrm{b}-\varepsilon_{s} ; \mathrm{c}-\varepsilon_{f}$ a)

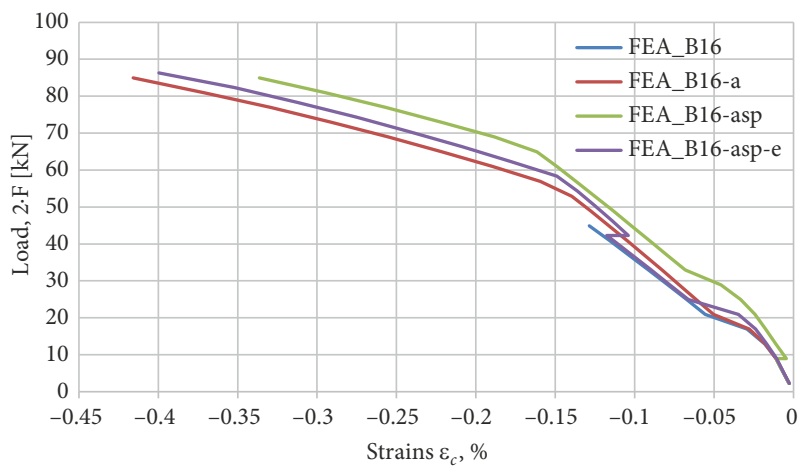

b)

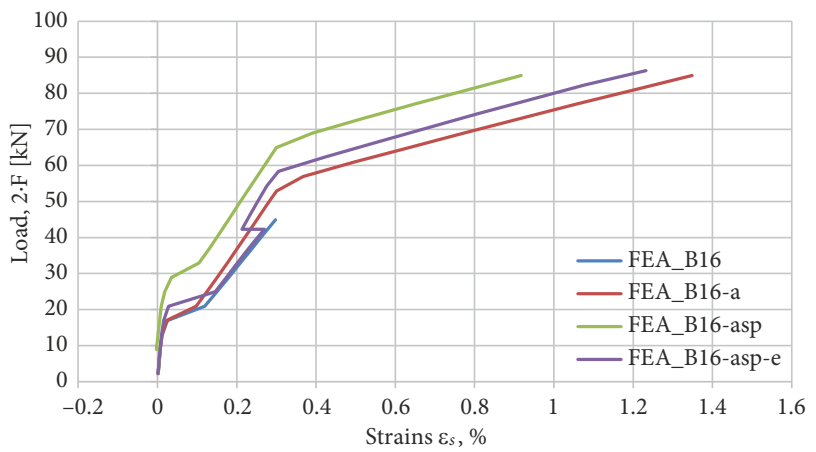

c)

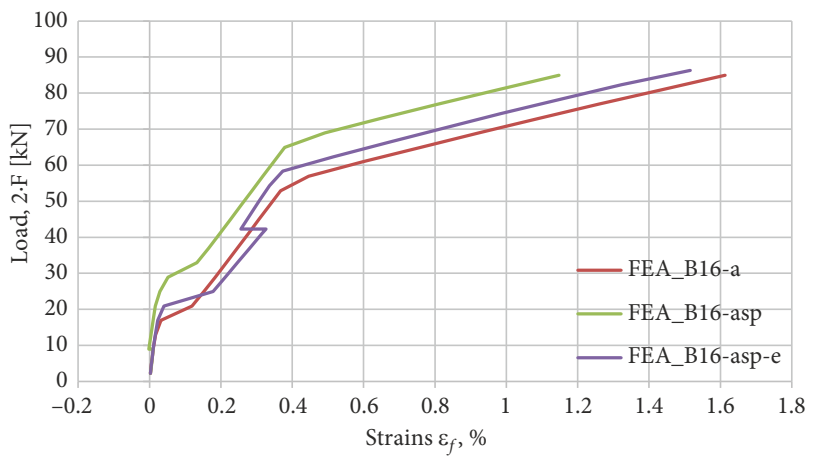

Fig. 9. External load vs strain, curves predicted numerically reinforcement, $4 \varnothing 16: \mathrm{a}-\varepsilon_{c} ; \mathrm{b}-\varepsilon_{s} ; \mathrm{c}-\varepsilon_{f}$ 


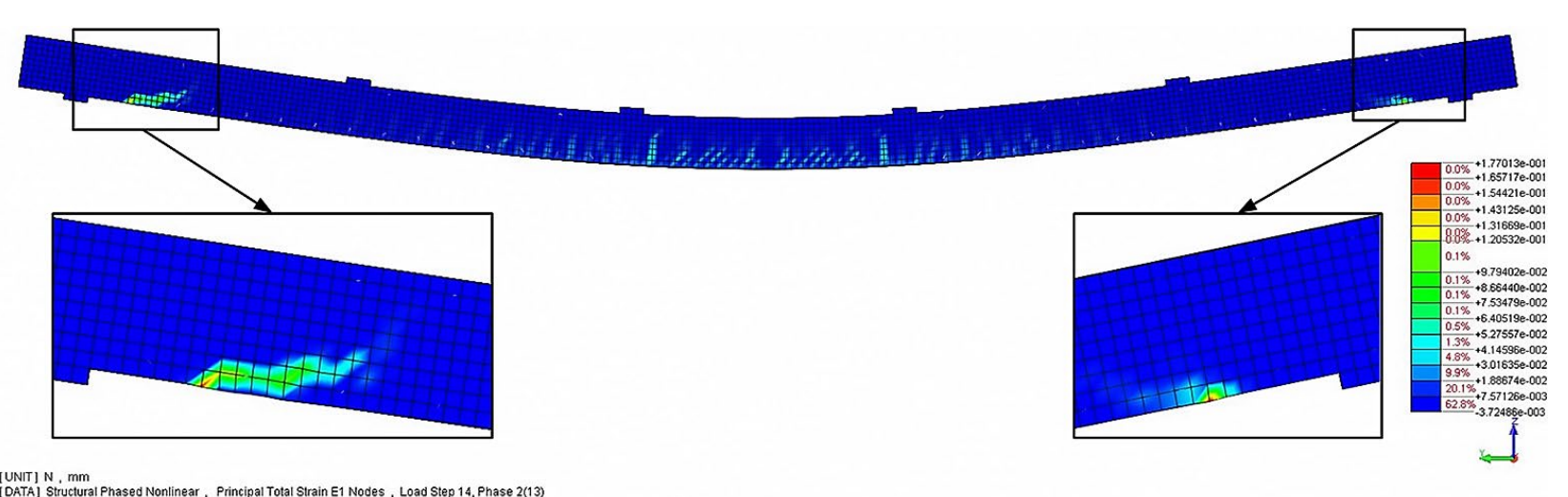

[UNITI N, mm
[DATA] Structural Phased Nonlinear, Principal Total Strain E1 Nodes, Load Step 14, Phase 2(13)

Fig. 10. View of the beam in FEM model at failure

If reinforcement ratio is small, like in the beams with reinforcement $4 \varnothing 12$, the depth of the neutral axis is small and consequently develops smaller strains on the top part of the section. It can be concluded that just in the beams FEA_B12-a and FEA_B12-asp-e the crushing of compressed concrete is reached. Ultimate strain of CFRP was not reached, so failure criteria for these beams are associated with concrete crushing in the compressed part of the section. Meanwhile failure criteria of the beams FEA_B12-asp can be associated with the peeling of the CFRP layer. Tensile strains of concrete at the ends of CFRP layer develops greater (Fig. 10) and this promotes peeling of CFRP layer with unsealed individual pieces of concrete.

Failure criteria of the strengthened beams with reinforcement $4 \varnothing 16$ are associated with crushing of compressed concrete. The greater reinforcement ratio creates greater depth of the neutral axis and consequently bigger strains develop. Therefore failure can occur at the lower developed curvature in comparison with curvature developed in the beams with reinforcement $4 \varnothing 12$.

\section{Conclusions}

Nonlinear numerical analysis has showed that it is possible to predict behaviour of the bending reinforced concrete elements strengthened with prestressed CFRP. Use of modern finite element analysis program allows setting up such important load-deflection points like cracking moment, yielding moment, and recovered deflection. Strengthening with prestressed CFRP positively affected the increment of deflection in case when the strengthening was accomplished for loaded beam.
If not a cracked beam is strengthened, only the cracking moment increases, and increment of deflection after the cracking remain the same like in the beams which were strengthened without prestressed CFRP. Applying of prestressed CFRP allowed increasing depth of the neutral axis. This positively affects growth of the deflection, because bigger area of compressed part of the section has created the bigger stiffness. Development of compressive strains in the beams which were strengthened with prestressed CFRP shows that increment of plastic strains decreases. This is especially good when the long term load is acting.

\section{Notations}

$A_{s}$ - cross section of reinforcement (steel bars);

$E_{c}$ - modulus of elasticity of concrete;

$E_{f}$ - modulus of elasticity of CFRP;

$E_{s}$ - modulus of elasticity of reinforcement (steel bars);

$F_{u}$ - ultimate load;

$G_{f c}$ - fracture energy of compressive concrete;

$G_{F}$ - fracture energy of tensile concrete;

$G_{F 0}$ - the base value of tensile concrete fracture energy;

$b$ - breadth of the cross-section;

$f_{c}$ - compressed strength of concrete;

$f_{c m}$ - average compressive strength of concrete;

$f_{c m 0}$ - constant compressive strength equal to $10 \mathrm{MPa}$;

$f_{c t}$ - concrete tensile strength;

$f_{\text {ct.sp }}$ - tensile splitting strength of concrete;

$f_{f}$ - tensile strength of CFRP;

$f_{y}$ - yielding strength of steel bars;

$h$ - height of the cross-section. 


\section{References}

Badawi, M.; Soudki, K. 2009. Flexural strengthening of RC beams with prestresses NSM CFRP rods - experimental and analytical investigation, Construction and Building Materials 23: $3292-3300$.

https://doi.org/10.1016/j.conbuildmat.2009.03.005

CEB-FIP Model Code 1990: Design Code. Comité Euro-International du Béton, 1991, 1993.

Deng, Z.-c.; Xiao, R. 2010. Flexural performance of RC beams strengthened with prestressed AFRP sheets: part I. experiments, in CICE 2010 - The 5th International Conference on FRP Composites in Civil Engineering, 27-29 September 2010, Beijing, China.

Diab, H.; Wu, Z.; Iwashita, K. 2009. Short and long-term bond performance of prestressed FRP sheet anchorages, Engineering Structures 31: 1241-1249. https://doi.org/10.1016/j.engstruct.2009.01.021

EN 1992-1-1:2004. Eurocode 2: Design of concrete structures Part 1: General rules and rules for buildings.

Garden, H. N.; Hollaway, L. C. 1998. An experimental study of the failure modes of reinforced concrete beams strengthened with prestressed carbon composite plates, Composites Part B 29B: 411-424. https://doi.org/10.1016/S1359-8368(97)00043-7

Garden, H. N.; Hollaway, L. C.; Thorne, A. M. 1998. The strengthening and deformation bahaviour of reinforced concrete beams upgraded using prestressed composite plates, Materials and Structures 31: 247-258. https://doi.org/10.1007/BF02480423

Huang, Y.-1.; Wu, J.-h.; Yen, T.; Hung, C.-h.; Lin, Y. 2005. Strengthening reinforced concrete beams using prestressed glass fiber-reinforced polymer - part i: experimental study, Journal of Zhejiang University Science 6A(3): 166-174. https://doi.org/10.1631/jzus.2005.A0166

Kotynia, R.; Lasek, K.; Staskiewicz, M. 2014. Flexural behavior of preloaded RC slabs strengthened with prestressed CFRP laminates, Journal of Composites for Construction 18(3): A4013004. https://doi.org/10.1061/(ASCE)CC.1943-5614.0000421

Liang, J.; Yu, D.; Wang, J.; Yi, P. 2016a. Mechanical properties of concrete beams reinforced with CFRP prestressed prisms under reverse cyclic loading, Computers and Concrete An International Journal 18(3): 355-366.

https://doi.org/10.12989/eas.2016.11.2.315

Liang, J.; Yu, D.; Yang, Z.; Chai, X. 2016b. Tests of concrete slabs reinforced with CFRP prestressed prisms, Earthquakes and Structures an International Journal 11(2): 315-326.

https://doi.org/10.12989/cac.2016.18.3.355

Lourenco, P. B. 1996. A user/programmer guide for the micro-modeling of masonry structures. TU-DELFT report No. 03.21.1.31.35, TNO-BOUW report no. 96-NM-R1201.

Manie, J.; Kikstra, W. P. 2011. DIANA finite element analysis user's manual analysis procedures release 9.4.4. 1st ed. TNO DIANA BV, Delft, The Netherlands.

Quantrill, R. J.; Hollaway, L. C. 1998. The flexural rehabilitation of reinforced concrete beams by the use of prestressed advanced composite plates, Composites Science and Technology 58: $1259-1275$. https://doi.org/10.1016/S0266-3538(98)00002-5

Shang, S.; Zhang, B.; Wu, J. 2010. Long-term performance research on reinforced concrete beams with prestressed CFRP, Procedia Engineering 4: 341-346.

https://doi.org/10.1016/j.proeng.2010.08.039

Si-Larbi, A.; Agsossou, A.; Ferrier, E.; Michel, L. 2012. Strengthening RC beams with composite fiber cement plate reinforced by prestressed FRP rods: experimental and numerical analysis, Composite Structures 94(3): 830-838.

https://doi.org/10.1016/j.compstruct.2011.10.001

Woo, S.-K.; Nam, J.-W.; Kim, J.-H. J.; Han, S.-H.; Byun, K. J. 2008. Suggestion of flexural capacity evaluation and prediction of prestressed CFRP strengthened design, Engineering Structures 30: 3751-3763. https://doi.org/10.1016/j.engstruct.2008.06.013

Xue, W.; Tan, Y.; Zeng, L. 2010. Flexural response predictions of reinforced concrete beams strengthened with prestressed CFRP plates, Composite Structures 92: 612-622. https://doi.org/10.1016/j.compstruct.2009.09.036

Yang, D.-S.; Park, S.-K.; Neale, K. W. 2009. Flexural behaviour of reinforced concrete beams strengthened with prestressed carbon composites, Composite Structures 88: 497-508. https://doi.org/10.1016/j.compstruct.2008.05.016

Mykolas DAUGEVIČIUS. Associate professor at the Department of Reinforced Concrete Structures and Geotechnics, Vilnius Gediminas Technical University. Research interests: the theory of reinforced concrete behaviour, composite materials and their calculation methods, rehabilitation of structures, thin walled structures. 